LA-UR- $02-5443$

Approved for publio release;

distribution is unlimited.
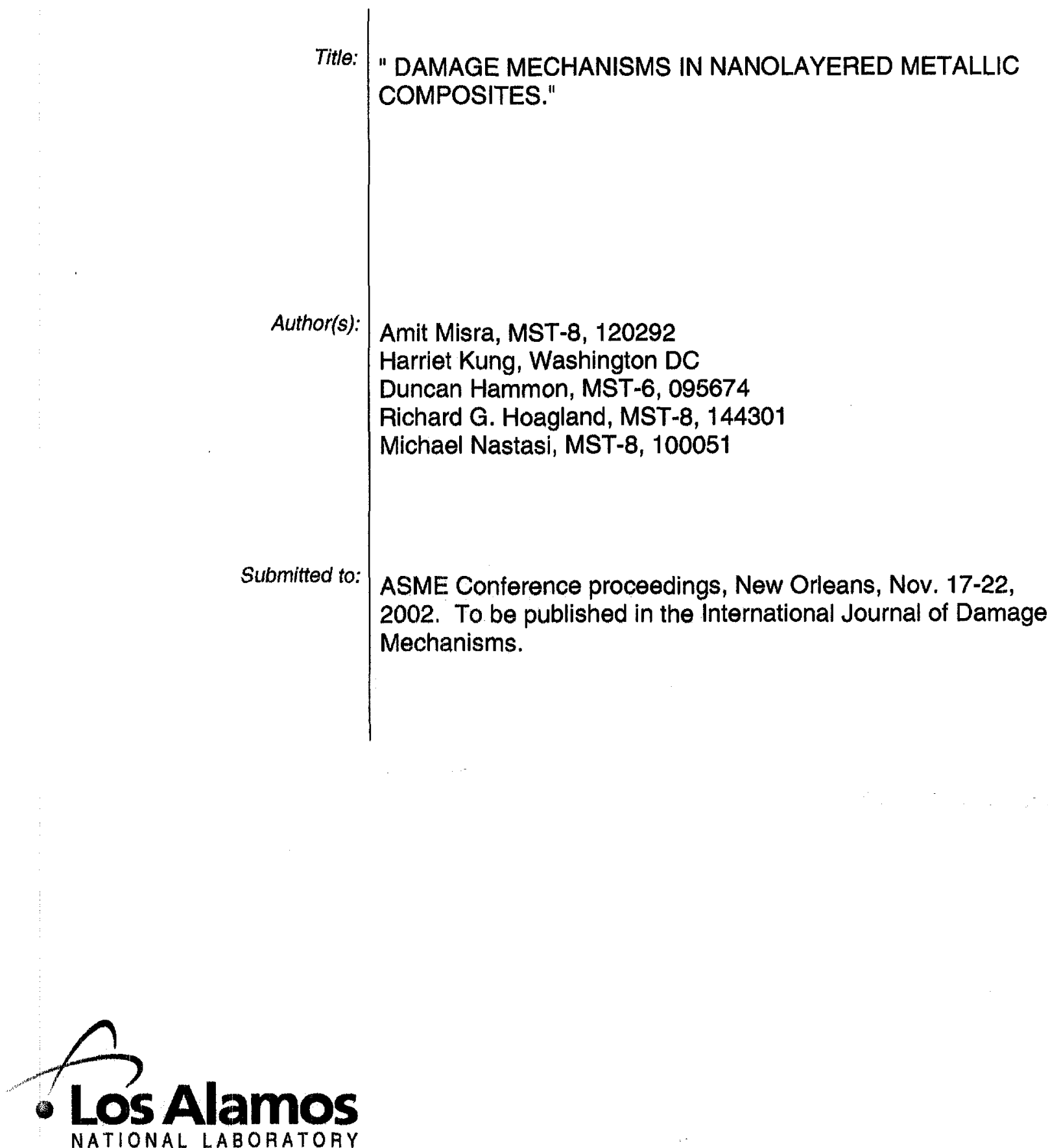

Los Alamos National Laboratory, an affirmative actlon/equal opportunity employer, is operated by the University of California for the U.S. Department of Energy under contract W-7405-ENG-36. By acceptance of this article, the publisher refognizes that the U.S. Government retains a nonexclusive, royalty-free license to publish or reproduce the published form of this con $\equiv$ ion, or to allow others to do so, for U.S. Government purposes. Los Alarnos Natlonal Laboratory requests that the publlsher identify this $D_{s}$ as work performed under the auspices of the U.S. Department of Energy. Los Alamos National Laboratory strongly supports academic freedom and a researcher's right to publish; as an institution, however, the Laboratory does not endorse the viewpoint of a publication or guarantee its technical correctness. 
Proceedings of IMECE02: 2002 International Mechanical Engineering Congress and Exposition, Symposium on Recent Advances in Damage Mechanics New Orleans, Nov 17-22, 2002

IMECE2002-TMMS-32395

\title{
DAMAGE MECHANISMS IN NANOLAYERED METALLIC COMPOSITES
}

\author{
A. Misra, H. Kung, D. Hammon, R.G. Hoagland and M. Nastasi,
}

Materials Science and Technology Division,

Los Alamos National Laboratory, Los Alamos, NM 87545

\begin{abstract}
The strengths of metallic multilayers, composed of alternating layers of soft metals such as $\mathrm{Cu}$ and $\mathrm{Nb}$, approach the theoretical limit of material strength when the bilayer periods are on the order of a few nanometers. We have investigated the damage mechanisms in these ultra-high strength nanolayered composite materials subjected to monotonic deformation, Large strain plastic deformation such as room temperature rolling does not lead to any dislocation cell structure formation within the layers indicating that the deformation and dislocation storage mechanisms in nanostructured materials are completely different from the bulk. In bulk metals, dislocation pile-ups lead to heterogeneous slip, but in nano-materials, deformation by single dislocations on closely spaced glide planes results in more homogeneously distributed slip. The implications of the high tensile strengths and homogeneous slip on the fatigue properties of nanolayered materials are also discussed.
\end{abstract}

\section{INTRODUCTION}

Deformation behavior of nanostructured materials has received significant interest recently due to the extremely high strengths observed in these materials. Two common synthesis methods used are: (i) severe plastic deformation of bulk materials [1], and (ii) vapor deposition [2]. In the first approach, heterogeneity of slip in bulk materials is utilized to continuously refine a micron-scale material with increasing amount of plastic deformation to tens to hundreds of nanometer scale. It is well established that plastic deformation in bulk materials involves groups or 'pile-ups' of dislocations gliding on planes that are widely spaced (on the order of a few $\mu \mathrm{m}$ in the early stages of plastic deformation). During plastic straining, these groups of dislocations organize themselves into dislocation boundaries that surround regions that are nearly-dislocation free. As the amount of plastic strain is increased, the misorientation angle across the dislocation boundaries increases and the spacing between these boundaries decreases. For very large strains (typically, a few hundred \%), the dislocation boundaries may evolve into high angle grain boundaries that are spaced on the order of a few hundred nanometers. In simple terms, this approach uses the accumulation and self-organization of 'dislocation damage' resulting from severe plastic deformation to refine a microstructured material to a nano-structured material. In contrast, the vapor deposited materials, which are the focus of this article, are directly synthesized as nanostructured materials. Using physical vapor deposition techniques such as electron beam evaporation and magnetron sputtering, we have synthesized nanolayered metallic composites where individual layer thickness may be as small as a few monolayers. While the evolution of hardness of these nanolayered metallic composites as a function of layer thickness has been studied $[2,3]$, little or no literature exists on studying the response of these materials to large plastic deformations. Specifically, we seek to understand the dislocation storage and recovery mechanisms in nanolayered metallic composites deformed to large plastic strains. Understanding damage accumulation mechanisins during plastic straining will be crucial to 
analyzing how these materials may behave under fatigue or creep conditions. In this article, we report on our ongoing study of the microstructure evolution, hardening and fracture of self-supported $\mathrm{Cu}-\mathrm{Nb}$ multilayers deformed by room temperature rolling.

\section{EXPERIMENTAL PROCEDURES}

$\mathrm{Cu}-\mathrm{Nb}$ multilayers were synthesized by dc magnetron sputtering at room temperature on $\mathrm{Si}$ or glass substrates. The layer thickness (i.e., one-half of the bilayer repeat length) varied from $1.2 \mathrm{~nm}$ to $2 \mu \mathrm{m}$. The samples with layer thickness of $2 \mu \mathrm{m}, 300 \mathrm{~nm}, 75 \mathrm{~nm}, 15 \mathrm{~nm}$ and $4 \mathrm{~nm}$ were used for rolling. The total thickness of these samples was in the 7-8 $\mu \mathrm{m}$ range. After deposition, the multilayered thin foils could be easily peeled off the substrates for rolling. The specimens were cut into strips about 1/2" wide and 1 "long and sandwiched between two stainless steel sheets, each about 250 $\mu \mathrm{m}$ thick, for rolling. Hardness of the multilayered thin foils was measured both before and after rolling using an indentation load-depth sensing apparatus, commercially available as Nano Indenter ${ }^{\circledR}$ II. Continuous stiffness technique was used for nanoindentation with a displacement rate of $10 \mathrm{~nm} / \mathrm{s}$. The nominal indentation depth was approximately $10 \%$ of the total sample thickness. The fractured multilayered foils were characterized using a JEOL 6300 FXV FEG scanning electron microscope (SEM) and the microstructures of the rolled foils were examined using a Philips CM30 transmission electron microscope (TEM).

\section{RESULTS AND DISCUSSION}

\section{Characterization of Sputter-deposited $\mathrm{Cu}-\mathrm{Nb}$ Multilayers}

The microstructure of the as-deposited $\mathrm{Cu}-\mathrm{Nb} 75 \mathrm{~nm}$ multilayer is shown in Fig. 1 that is a bright field (BF), crosssection TEM micrograph. The selected area diffraction pattern (SADP) in the inset in Fig. 1 indicates a $\{110\}$ bcc $/ /\{111\} \mathrm{fcc}$ $/ /$ interface plane texture in these multilayered films. The inplane nanocrystalline grains are columnar with widths on the order of the layer thickness for $\mathrm{Cu}$ and slightly lower for $\mathrm{Nb}$. The hardness of the as-deposited $\mathrm{Cu}-\mathrm{Nb}$ multilayers as a function of the inverse square root of the layer thickness (h) is shown in Fig. 2. Here, h corresponds to the thickness of an individual $\mathrm{Cu}$ (or, $\mathrm{Nb}$ ) layer in the multilayer, e.g., $\mathrm{h}=75 \mathrm{~nm}$ for the structure shown in Fig. 1. A linear relation between hardness and $\mathrm{h}^{-1 / 2}$ is consistent with the continuum-scale HallPetch model [4]: $\mathrm{H}=\mathrm{H}_{0}+\mathrm{kh}^{-1 / 2}$ (1) where $\mathrm{H}_{0}$ represents the lattice friction stress and $\mathrm{k}$ ( $\mathrm{H}-\mathrm{P}$ slope) indicates the relative hardening contribution from grain or interphase boundaries. The model is applicable to both hardness and strength data, and to hardening due to grain refinement in single-phase metals as well as hardening due to inter-lamellar refinement in two-phase lamellar materials. We note from the linear fit in Fig. 2 that eq. (1) describes the hardness increase with decreasing $h$ only for large values of $h$. Small deviations from

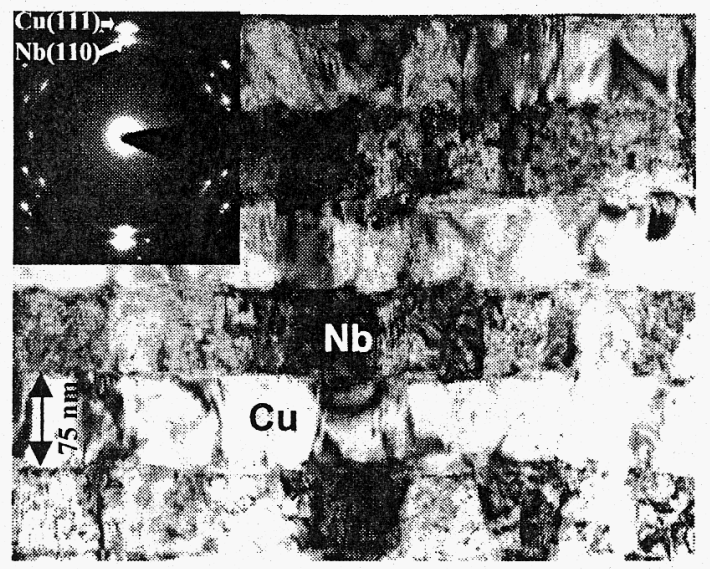

Fig. 1 TEM image showing the microstructure of asdeposited $\mathrm{Cu}-\mathrm{Nb}$ multilayers. Inset shows the selected area diffraction pattern; note $\{110\} \mathrm{Nb} / /\{111\} \mathrm{Cu}$ texture.

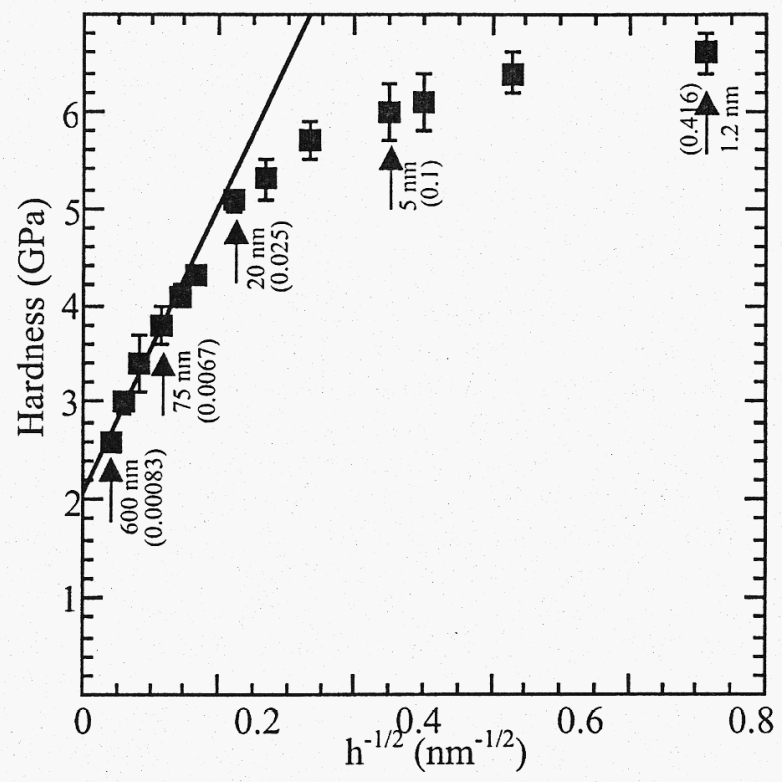

Fig. 2 Effect of layer thickness (h) on the hardness of $\mathrm{Cu}-\mathrm{Nb}$ multilayers. The continuum Hall-Petch model that predicts that hardness scales with the inverse square-root of $h$ is not valid when $h$ is on the order of a few to a couple tens of nanometers. For some data points marked with arrows, the corresponding $\mathrm{h}$ values are listed, and the numbers in parentheses are the interface area to bilayer volume ratio.

the Hall-Petch model can be seen at $\mathrm{h}<\sim 50 \mathrm{~nm}$, and for $\mathrm{h}<$ $20 \mathrm{~nm}$, hardening behavior in $\mathrm{Cu}-\mathrm{Nb}$ multilayers deviates significantly from the continuum-scale model prediction. Fig. 2 also shows how the fraction of atoms at interfaces (proportional to the interface area to the bilayer volume ratio) increases with decreasing $\mathrm{h}$ in these nanolayered materials. This indicates that continuum-scale models such as Hall-Petch 
are applicable when atoms in the bulk control the behavior. When the fraction of atoms at interfaces increases significantly above $1 \%$, new concepts are needed to interpret the interface-controlled plasticity in nanostructured metals. Specifically, this refers to the discrete phenomenon such as nucleation and motion of single dislocations (as opposed to groups) that become critical in nano-scale materials when the interface-to-interface distance is so small that the number of dislocations in a pile-up approaches one [5]. The effect of this change in plasticity behavior from continuum to discrete at nano-scales on the damage accumulation is described next.

\section{Characterization of Rolled $\mathrm{Cu}-\mathrm{Nb}$ Multilayers}

Fig. 3 shows the microstructures of $\mathrm{Cu}-\mathrm{Nb}$ multilayers after rolling. The multilayer with initial $\mathrm{h}=2 \mu \mathrm{m}$ exhibited the classical dislocation cell sub-structure after 50\% reduction in
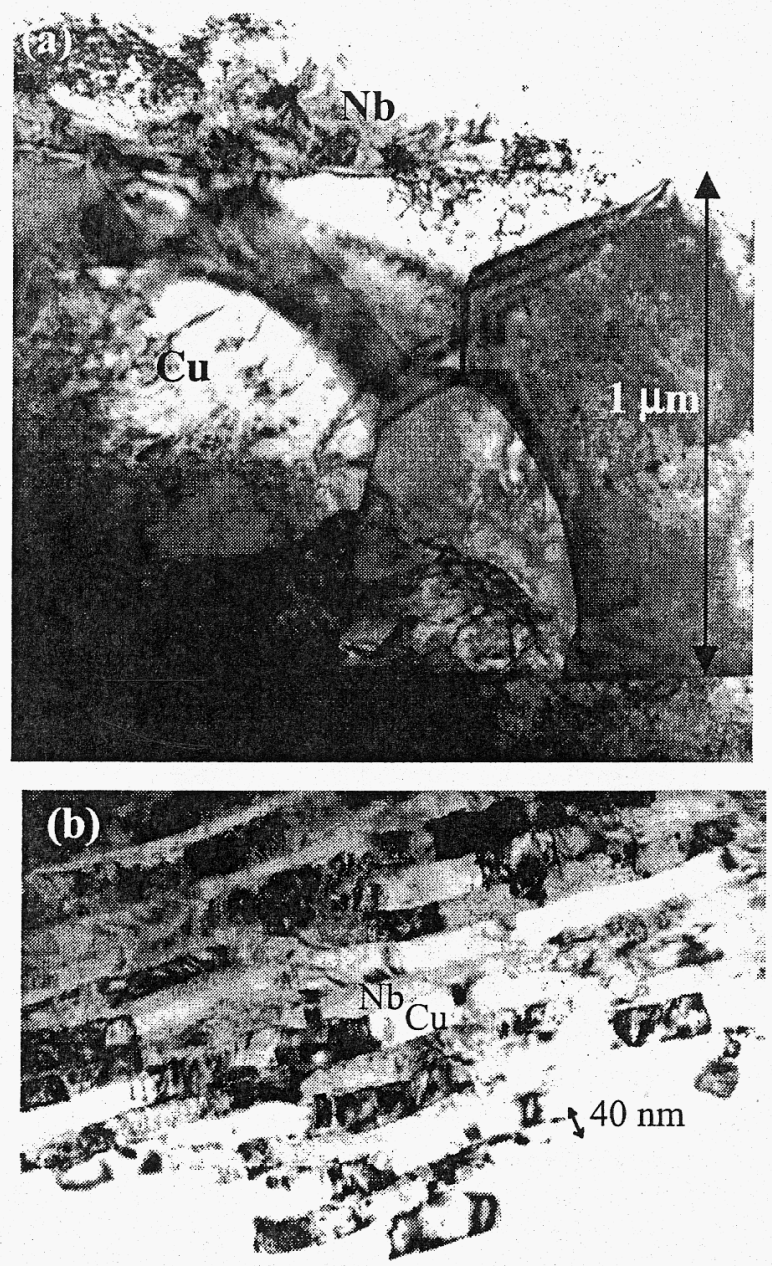

Fig. 3 TEM images showing microstructures after rolling in $\mathrm{Cu}-\mathrm{Nb}$ multilayers; (a) $2 \mu \mathrm{m}$ initial layer thickness reduced to $1 \mu \mathrm{m}$, and (b) $75 \mathrm{~nm}$ initial layer thickness reduced to $40 \mathrm{~nm}$. Note cell structure in (a) and absence of dislocation tangles or cell structures in (b).

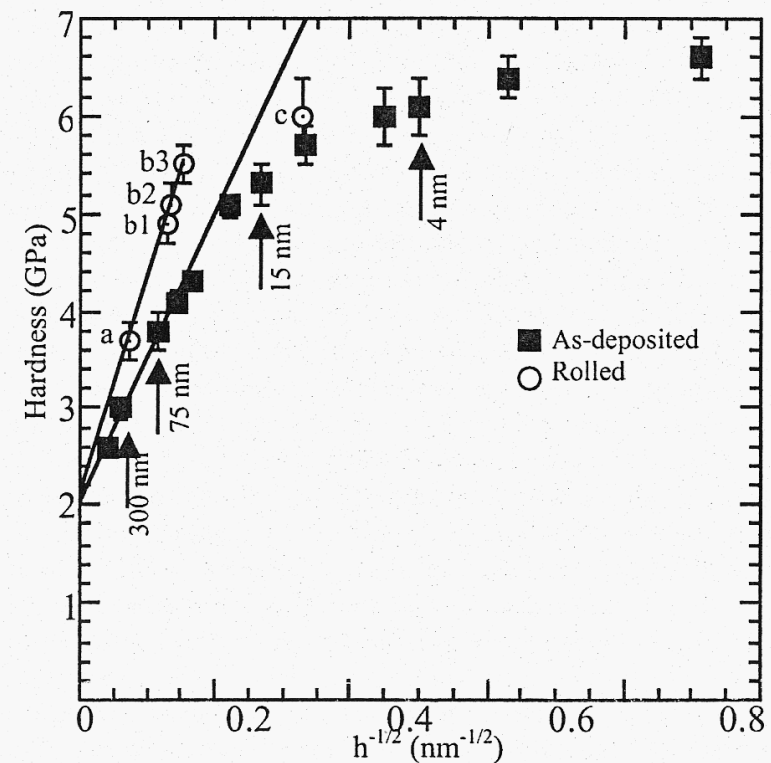

Fig. 4 Effect of rolling on the hardness of $\mathrm{Cu}-\mathrm{Nb}$ multilayers. For rolled samples, the data point labeled a represents a sample with initial $\mathrm{h}=300 \mathrm{~nm}$ rolled to $37.5 \%$ reduction. Data points b1, b2 and b3 are from samples with initial $h=75$ $\mathrm{nm}$ rolled to $20 \%, 27 \%, 43 \%$ reductions, respectively. Data point $\mathrm{c}$ is from a sample with initial $\mathrm{h}=15 \mathrm{~nm}$ rolled to $37.5 \%$ reduction.

rolling (Fig. 3(a)). The sub-grains in the $\mathrm{Cu}$ layer are typically $0.4-0.5 \mu \mathrm{m}$ in size. In the Nb layers, the cell structure was less pronounced, and mostly dense dislocation tangles and walls were observed. However, the multilayer with initial $\mathrm{h}=75 \mathrm{~nm}$ did not exhibit any cell sub-structure even after $\sim 50 \%$ reduction in rolling, although the $\mathrm{Cu}$ and $\mathrm{Nb}$ layers were reduced in thickness uniformly (Fig. 3(b)). Some grains did show single dislocations in a layer, often as an array, pinned at $\mathrm{Cu} / \mathrm{Nb}$ interfaces. More details of the characterization of dislocation substructures are presented elsewhere [6]. This observation raises important questions about how the cooperative dislocation motion is accomplished in nano-scale materials without accumulating any substructure within the grains. Lack of dislocation cell sub-structure formation in nanolayered materials also resulted in new kinds of deformation textures that are completely different from the rolling textures in micron-scale materials. Textures data are presented elsewhere [6]. We believe that the trend in substructure evolution is consistent with the transition from continuum (pile-up) to discrete (single dislocation) behavior at nano-scales and discuss it in more detail later in the article.

We next consider how the hardness of the $\mathrm{Cu}-\mathrm{Nb}$ multilayers is affected by rolling. Fig. 4 compares the hardness of some of the rolled multilayers to the hardness in the asdeposited state. In Fig. 4, the data point labeled ' $a$ ' is from a 
sample with initial $\mathrm{h}=300 \mathrm{~nm}$ rolled to $37.5 \%$ reduction. The data points labeled ' $b 1$ ', ' $b 2$ ' and ' $b 3$ ' are from samples with initial $\mathrm{h}=75 \mathrm{~nm}$ rolled to $20 \%, 27 \%$, and $43 \%$ reductions, respectively, and the data point $\mathrm{c}$ is from a sample with initial $\mathrm{h}=15 \mathrm{~nm}$ rolled to $37.5 \%$ reduction. Note that in the rolled samples the data points $a, b 1, b 2$ and $b 3$ fall on a straight line that has a higher slope than the Hall-Petch slope of the asdeposited samples, while the data point $\mathrm{c}$ is the regime where Hall-Petch relation breaks down. The higher Hall-Petch slope of rolled samples indicates a work hardening contribution from rolling. For example, consider a sample with initial $h=75$ $\mathrm{nm}$ rolled to $20 \%$ reduction, i.e., final layer thickness of 60 $\mathrm{nm}$. The rolled sample with $\mathrm{h}=60 \mathrm{~nm}$ is harder than an asdeposited sample with $\mathrm{h}=60 \mathrm{~nm}$. This additional hardening in rolled multilayers when compared to the hardness of the asdeposited multilayers of equal layer thickness is what we refer to as the work hardening due to rolling. For micron-scale materials, it is clear that this work hardening can be attributed to the cell structure formation within the layers [7]. However, for nano-scale materials, the source of work hardening, in the absence of dislocation cell structure, is not obvious. An increased Hall-Petch slope in rolled multilayers would be consistent with an increased resistance to slip transmission across interfaces after rolling [8]. Since the crystallography of the interface does not change during rolling, i.e., the $\{111\} \mathrm{Cu} / /\{110\} \mathrm{Nb} / /$ interface plane orientation is maintained, the dislocation content deposited at the $\mathrm{Cu} / \mathrm{Nb}$ interface as single dislocations are transmitted across the interface, could account for the interfaces becoming stronger barriers to slip after rolling. The dislocation content may be deposited initially by the motion of Orowan type dislocation loops that glide in a 'hairpin' configuration parallel to the interfaces. The segment of the glide dislocation deposited at the interface may then glide out in the other layer leaving behind a dislocation segment at the interface that accounts for the difference in the magnitudes of the Burgers vectors in $\mathrm{Cu}$ and $\mathrm{Nb}$. This residual Burgers vector often has a step character associated with it. In fact, atomistic simulations for the case of $\mathrm{Cu}-\mathrm{Ni}$ have shown that each slip transfer event creates a small step at the interface and locally increases the resistance of the interface to subsequent slip transmission [9]. If this kind of dislocation storage at the interface continued to very large strains, it might result in amorphization at interfaces, as reported for cold drawn $\mathrm{Cu} / \mathrm{Nb}$ wires [10]. More careful characterization of the interfaces is needed to look for evidence of amorphization at the interfaces in the cold rolled multilayers studied here. We speculate that a more reasonable scenario would be that some kind of recovery mechanism gets activated at the interface as the stored dislocation density increases. This would imply that the work hardening would reduce in magnitude at large strains. From the data presented here it is not possible to determine the work hardening behavior as a function of rolling strain, since layer thickness also varies with rolling strain. The effect of rolling strain on the work hardening, at a constant layer thickness, will be studied in our future work.
An alternate view of the "work hardening" during rolling is the suppression of dislocation sources. A comparison of the as-deposited (Fig. 1) and rolled (Fig. 3(b)) microstructures indicates coarsening of the in-plane grains after rolling, presumably related to the in-plane texturing in rolling and facilitated by the removal of the low angle grain boundaries that exist in sputtered films. Furthermore, low dislocation density is evident within the grains. Hence, it is possible that the "work hardening" mechanism may involve the difficulty of activating dislocation sources in rolled nanolayered metals.

Continued rolling, (typically, $\sim 3 \%$ reduction was used per pass), resulted in the formation of through thickness microcracks in the foils. An example is shown in Fig. 5 from a $\mathrm{Cu}-$ $\mathrm{Nb}$ multilayer with initial $\mathrm{h}=15 \mathrm{~nm}$ rolled to $50 \%$ reduction. This SEM micrograph of the surface of a rolled foil shows cracks oriented perpendicular to the rolling direction. For the case shown in Fig. 5, the cracks were spaced about $50 \mu \mathrm{m}$ (the total initial sample thickness was $7.5 \mu \mathrm{m}$ ) and were about 200 $\mu \mathrm{m}$ long, on average. With such a distribution of micro-cracks, the multilayered foil was perforated but the sample was still in one piece. Perhaps the most significant observation in Fig. 5 is that the fracture appears to be by shear cracks. The crack plane
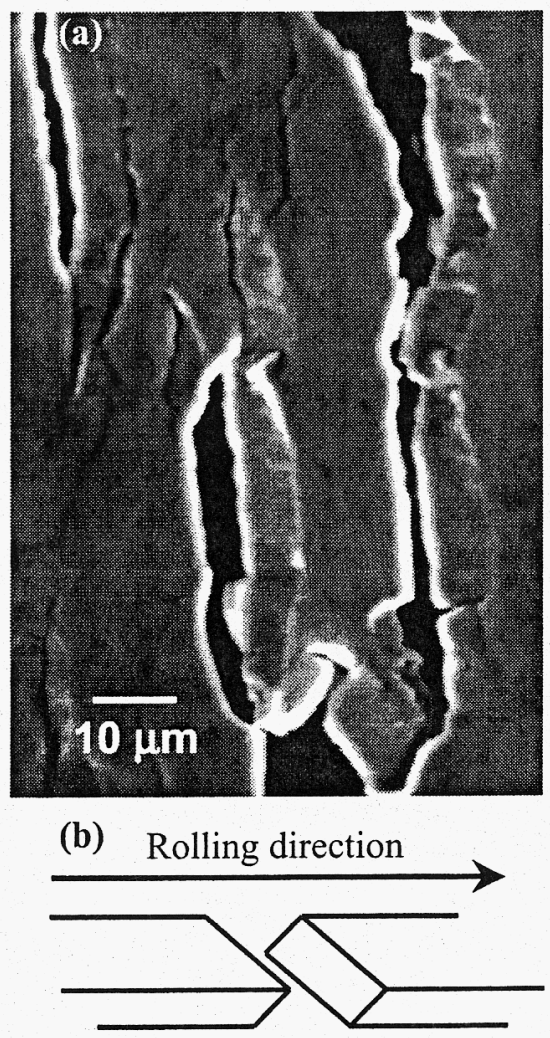

Fig. 5 (a) SEM image of the surface of a $\mathrm{Cu} / \mathrm{Nb}$ multilayer with an initial layer thickness of $15 \mathrm{~nm}$ rolled to $50 \%$ reduction; (b) schematic illustration of the shear,cracks. 
is not normal to the rolling direction, rather inclined and roughly along the planes of maximum shear stress. The effect of layer thickness on the rolling strain to fracture is shown in Fig, 6 . For the three samples ( $h=4 \mathrm{~nm}, 15 \mathrm{~nm}$, and $75 \mathrm{~nm}$ ), where rolling was continued to fracture, the strain to the onset of shear cracking reduces with decreasing initial $h$. While samples with $\mathrm{h}=75 \mathrm{~nm}$ and $\mathrm{h}=15 \mathrm{~nm}$ could be reduced to $\sim 65 \%$ and $-38 \%$ strains, respectively, before throughthickness shear cracks were observed, the sample with $\mathrm{h}=4 \mathrm{~nm}$ exhibited cracking in the first pass itself. We hypothesize that there are two factors that may determine the deformability limit in these nanoscale rolled multilayers. First, there is a critical value of hardness (approximately, $6 \mathrm{GPa}$ from Fig, 4), above which yield strength exceeds the shear fracture stress. Hence, the $\mathrm{Cu}-\mathrm{Nb}$ multilayers that have hardness above this critical value in the as-deposited state will exhibit fracture prior to yield (e,g, $h=4 \mathrm{~nm}$ ). The multilayers with hardness below this critical value will work harden during rolling till the strength exceeds the shear fracture stress. The second factor that determines the strain to fracture is the layer thickness itself, particularly for layer thickness in the couple to a few nanometers range. When $h$ is only a couple nanometers, it takes only 10-12 dislocations to glide on the same plane to shear a layer (analogous to particle shearing by gliding dislocations in under-aged precipitation hardening alloys). For the $\mathrm{Cu}-\mathrm{Nb}$ multilayers rolled to fracture here, it appears that the first condition described above determined the deformability limit. It is unclear what determines the critical value of the hardness at which the yield strength exceeds the shear fracture stress, but a possible explanation is discussed in the next section.

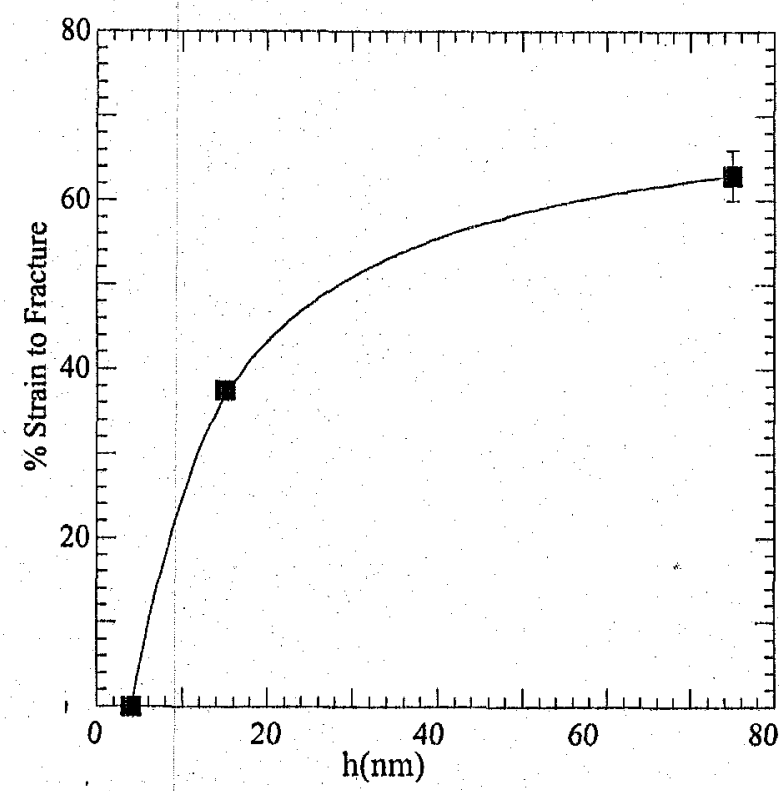

Fig. 6 Plot of \% strain (reduction) to fracture as a function of initial layer thickness of $\mathrm{Cu}-\mathrm{Nb}$ multilayers.
We now discuss the key differences between the damage mechanisms during plastic deformation of micron-scale and nanoscale multilayers, and the implications of these to properties such as fatigue resistance of nanostructured multilayers. Fig. 7 schematically shows how the microstructural length scale influences the slip distribution in materials. For micron-scale materials (Fig. 7(a)), plasticity is typically heterogeneous and confined to widely spaced slip bands. In each slip band, several parallel glide planes may be active with dislocations moving as groups (pile-ups) on each of the glide planes, and creating slip steps with a staircase-like contour at the intersection of these glide planes with the specimen surface. It is this heterogeneous slip that leads to the classical cell sub-structure formation observed in micron-scale materials (Fig. 3(a)). For the case of cyclic deformation, these slip bands are referred to as persistent slip bands (PSBs) and the back-and-forth fine slip movements in a PSB may create slip band intrusions and extrusions at the surface. Fatigue cracks invariably nucleate at the intrusion sites. As the microstructural length scale is decreased to the nanometer regime, continuum-scale dislocation pile-ups cannot form. At the few tens of nanometers regime, dislocation pile-ups are discrete, and at even lower length scales, the number of dislocations in a pile-up approaches one. For a given total plastic strain in a sample, the fewer the number of dislocations in each pile-up, the more closely spaced these pile-ups need to be (Fig. 7(b)). Hence, the primary effect of discrete pile-up or single dislocation behavior is that plasticity is more

(a)

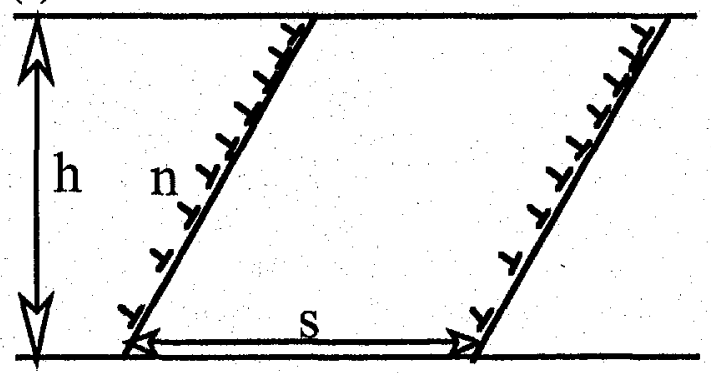

(b)

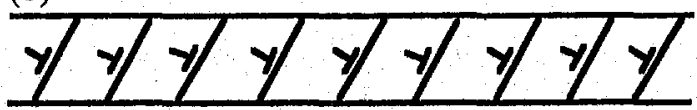

Fig. 7 Schematic of the effect of microstructural length scale on the slip distribution in nanolayered metals. (a) when $\mathrm{h}$ is micron-scale, dislocation pile-ups are widely spacced (s) and each pile-up may have a large number $(\mathrm{n})$ of dislocations resulting in heterogeneous slip; (b) when $\mathrm{h}$ is nano-scale, $\mathrm{n}$ approaches one. Slip is homogeneously distributed by single dislocations gliding on closely spaced planes. 
homogeneously spread in the material. This is manifested in dislocation substructure evolution also (Fig. 3(b)) where no cell sub-structure was observed. With less strain localization and lack of any PSB formation, such materials may also have high fatigue strengths in addition to the high strengths in monotonic tests reported here. The response of these materials to cyclic deformation will be investigated in our future work.

Finally, we discuss the fracture of the multilayered foils during rolling. Presumably, the lack of strain localization allowed significant plasticity in rolled $\mathrm{Cu}-\mathrm{Nb}$ nanolayered composites with $h$ in the few tens of nm range. However, as the layer thickness was decreased from a few tens to a few nanometers regime, no plasticity was observed in rolling. To interpret this behavior, first we consider the behavior at length scales (tens of $\mathrm{nm}$ regime for $\mathrm{Cu}-\mathrm{Nb}, \mathrm{Fig}$. 2) where the continuum Hall-Petch model is not valid, but the strength continues to increase with decreasing layer thickness. In this length scale regime, plastic flow may initially be confined to one layer and occur by the motion of single "hairpin" dislocation loops that deposit misfit type dislocations at the interface and transfer load to the other, elastically-deforming layer [5]. This process of forming arrays of Orowan type single dislocation loops on one side of the interface prior to slip transfer in effect spreads the slip homogeneously in the layer, and also leads to high work hardening. The composite yield occurs when slip is eventually transmitted across the interface. With this Orowan type behavior, the multilayers are likely to possess deformability and work hardening. The Orowan stress for bowing of 'hairpin' dislocation loops confined to a layer scales inversely with layer thickness. At a few nanometers, this stress may exceed the stress for transmission of single dislocations across the interface. Hence, slip transmission would occur prior to homogeneous spread of slip in the layers, and may mark the onset of shear instability observed in the very finest-scale multilayers (e.g, $h=4 \mathrm{~nm}$ ) studied here. In this regime, a weak or no dependence of hardness on layer thickness is observed since the Orowan mechanism is no longer applicable. Therefore, the work hardening behavior during rolling of nanolayered materials appears to be valid in the length scale regime where in the asdeposited condition strength still increases with decreasing layer thickness via the Orowan mechanism.

\section{SUMMARY}

Cold rolling of sputter-deposited $\mathrm{Cu}-\mathrm{Nb}$ multilayers was used to study the effect of microstructural length scale on the evolution of damage mechanisms with increasing plastic deformation. For micron-scale multilayers, the wellestablished heterogeneous plasticity behavior was observed where a dislocation cell sub-structure evolves and the cell size continuously diminishes with increasing strain. The nanolayered $\mathrm{Cu}-\mathrm{Nb}$ materials, however, exhibited uniform reduction in layer thickness without any evidence of cell structure formation. The transition from continuum-scale dislocation pile-ups in bulk materials to discrete pile-up or single dislocation behavior in nano-scale materials is believed to responsible for the increased homogeneity in slip with decreasing length scales. The nano-scale multilayers exhibited work hardening during rolling till the strength of the multilayer exceeded the fracture stress leading to throughthickness shear cracks in the foils. $\mathrm{Cu}-\mathrm{Nb}$ multilayers that had higher yield strength than the stress for shear cracking in the as-deposited condition exhibited no deformability in rolling. The high strengths of these nanolayered metallic composites and the homogeneously distributed slip patterns indicate that these materials may have high fatigue strengths as well.

\section{ACKNOWLEDGEMENTS}

This research is funded by DOE, Office of Basic Energy Sciences. We acknowledge discussions with J.P. Hirth, J.D. Embury and $P$. Anderson. The assistance of $R$. Hainmon with rolling and TEM specimen preparation is acknowledged.

\section{REFERENCES}

1. D.A. Hughes and N. Hansen, Phys. Rev. Lett., 87, 13, 5503 (2001).

2. B.M. Clemens, H. Kung and S.A. Barnett, MRS Bulletin, 24, 20, February (1999).

3. A. Misra and H. Kung, Advanced Engineering Materials, April, 217 (2001).

4. N.J. Petch, J. Iron Steel Inst. London, 173, 25 (1953).

5. J.D. Embury and J.P. Hirth, Acta Met., 42, 2051 (1994).

6. H. Kung, et al., Los Alamos National Laboratory, unpublished research.

7. F.R.N. Nabarro, Z. S. Basinski and D.B. Holt, Adv. Phys., 13, 193 (1964).

8. J.G. Sevillano, in "Plastic Deformation and Fracture of Materials", ed. by Hael Mughrabi, Materials Science and Technology-A Comprehensive Treatment, vol.6, VCH, New York, 1993.

9. R.G. Hoagland, T.E. Mitchell, J.P. Hirth and H. Kung, Phil Mag A, 82, 643 (2002).

10. X. Sauvage, L. Renaud, B. Deconihout, D. Blavette, D.H. Ping, K. Hono, Acta Mat., 49, 389 (2001). 